\title{
Las cartas de Abdessalam Bennuna a Chakib Arsalan sobre el dahir bereber
}

\author{
Abdessalam Bennuna's letters to Chakib Arsalan on the Berber Dahir
}

Nazha ABOUBEKER

aboubekernazha@gmail.com

Para citar este artículo: Nazha ABOUBEKER (2018), "Traducción de Las cartas de Abdessalam Bennuna a Chakib

Arsalan sobre el dahir bereber" en Revista de Estudios Internacionales Mediterráneos, 24, 211-234.

Para acceder a este artículo: https://doi.org/10.15366/reim2018.24.012

\section{Presentación}

\section{Nota introductoria a la traducción}

En junio de 1982 Nazha Aboubeker se licenció en Lengua y Literatura Españolas en la Universidad Sidi Mohamed Ben Abadía de Fez (Marruecos) con una monografía de licenciatura titulada "El dahir Berber y el nacionalismo marroquí en la zona del Protectorado español. Estudio y traducción de las cartas de "Abd Salam Bennuna a Saquib Arsalan" que le dirigí. Se acababan de publicar los originales árabes de las cartas poco antes por Mohamed Ben 'Azuz Hakim (Wațāiq sirrīya ḥawla ziyārat al-amīr Šakīb Arslān li-l-Maġrib, Cartas secretas que conciernen a la visita de Šaquib Arsalan a Marruecos, Edición Fundación Abdeljalek Torres, Tetuán 1980). Por entonces, el grupo de profesores españoles del departamento de hispánicas de la citada Universidad (Manuel Bayo García, Domingo García Cañedo, José María Alfaya y yo mismo) habíamos decidido explotar para las "tesinas" de nuestros estudiantes el filón de los materiales de la Biblioteca Española de Tetuán (entre ellos inmensas colecciones de periódicos del Protectorado) así como textos de utilidad para el conocimiento de esa faceta poco conocida de la historia española de allá del Estrecho.

La tesina que Nazha Aboubeker abordó con mucha desenvoltura consistió en un estudio de unas 40 páginas a ciclostil sobre el nacionalismo marroquí y las consecuencias del Dahir Bereber y en la traducción de las cartas del padre del nacionalismo marroquí del Norte, Abdessalam Bennuna, al Emir Chakib Arsalan tras la visita de este al Protectorado español, fechadas entre 1930-31. 
Siempre pensé que el destinatario de aquella traducción debía ser el lector español, pero nunca quise darlo a la luz sin el consentimiento de la traductora. Aun así utilicé dichas traducciones para un curso monográfico sobre nacionalismo marroquí en 2009 y pedí a dos de mis estudiantes de aquel curso, Alejandro Rabanal Márquez y Lorena Crespo Rodríguez, que transcribieran la tesina original a Word. Aprovecho esta nota para agradecerles su trabajo.

En noviembre de 2017 Facebook me dio la oportunidad de reencontrarme con Nazha Aboubeker, quien, muy gustosamente, me dio la autorización para publicar con su nombre la traducción. La REIM tiene ahora la oportunidad de publicarla en la seguridad de que constituye un documento de gran utilidad para los interesados en la historia del nacionalismo marroquí. Se respeta la transcripción que la traductora hizo de los nombres en árabe y se han incorporado algunas notas para clarificar el contenido de algunos aspectos de la correspondencia.

Bernabé López García

\section{Carta ํㅜ 1:}

Loor a Dios:

Su gracia glorioso y respetable Emir, señor Saquib Arsalan ¡Dios altísimo le proteja!

Excelente señor, me ha honrado su carta fechada en Madrid, el 14 de Septiembre, por lo que he dado gracias a Dios por su salud, y por su seguridad. No quería responder hasta que encontrase algunos de los libros históricos que me habías señalado, pero al no tener informaciones de los hombres encargados para hacerlo (y no sé por qué), he preferido responder a su alteza, para tener noticias suyas; además, he insistido sobre el asunto de los libros, con los mismos señores de antes: el Emir Zaydan, 'Abd Lhay Al Ketani, 'Abd Lwahed Al Fasi, Ŷa'far Anasiri y 'Abd Alah Al Katani que se ocupa de la biblioteca Ribat Al-Fath y cuando encuentre alguno de los libros informaré a su gracia.

Señor, estamos muy ilusionados porque su interesante revista "La nation arabe" informa del Dahir berber, deseando que no se haya perdido el número seis en el correo, o que no haya sido retenido. Queremos saber la respuesta del señor Ihsan Bik Al Ŷabiri, al que brindo mi saludo caluroso. No conocemos lo que ha hecho el líder Longuet ${ }^{1}$, en la revista "Le populaire", porque no llega a estos lugares. Mientras el señor Renaudel ${ }^{2}$, pienso que su alboroto va a ser en el parlamento.

Se ve también que los estudiantes marroquíes que residen en París, intentaron incluir algunos diputados parlamentarios, y por esta meta, habían enviado por medio de mi persona,

\footnotetext{
${ }^{1}$ Se refiere a Jean Longuet, nieto de Carlos Marx, redactor de L'Humanité y más tarde fundador de Le Populaire, periódico que seguirá en la onda de la SFIO. Su hijo Robert-Jean Longuet fundaría en julio de 1932 la revista anticolonialista Maghreb.

2 Pierre Renaudel (1871-1935), antiguo director de L'Humanité y diputado socialista de tendencia moderada.
} 
muchas cartas a un grupo de burgueses marroquíes, que he distribuido por medio del correo inglés. Estos estudiantes querían que os enviase su carta, y usted hará el favor de quemarla, según lo que han mandado.

Voy a hacer todo lo posible para llegar a reunir unas colaboraciones en la revista "La nation arabe", intentando con esto aminorar aún un poco la crisis de sus enormes gastos; ialabado sea Dios que nos ayude!

En las páginas de "Al Fath", he leído vuestra carta destinada al Ŝayj 'Abd Lhamid Sa'id, que la ha publicado sin firma, añadiéndole unas expresiones, que nos hacen comprender que la carta proviene de otra persona. Según las informaciones provenientes de los estudiantes marroquíes, en el "Azhar Aŝarif", hemos conocido que el dicho Aŝayj, había cumplido con todo lo que le habíais mandado, iqué Dios os agradezca! Mientras Muhib Adin Al Jatib, había hecho lo posible en la publicación, iDios le ayude!

El dueño de "Aŝora" había mandado lo que había tardado en llegar de sus números, pero no hemos encontrado el artículo señalado por usted, puede que se haya puesto furioso, iDios le muestra el buen camino!

Con esto vaya a encontrar la carta del señor Quadra Toqan y la de los jóvenes marroquíes iqué Dios les ayude! iDios el altísimo os proteja para apoyar el islam y los musulmanes! Quadra Toqan, es el profesor de gimnasia en la escuela "Al-Naŷah", que os he dicho al hablar de la traducción del libro del difunto Ahmed Mujtar Baša.

Señor, estamos muy ilusionados por saber los resultados de su entrevista con el rey Faysal, poniendo nuestras esperanzas en esta reunión, y os agradecemos el hecho de darnos unas informaciones deseando para la nación árabe y para los países del islam, que los acontecimientos sean buenos.

La revista "Al Ahram" había publicado en su número del 18 de Septiembre, un telegrama desde su despacho de París, sobre la conversación desarrollada entre él y Rino, el secretario general del instituto islámico, en la ciudad mencionada. $Y$ no cabe duda que estabais al corriente de esta impostura y engaño de ideas, y habíais visto que Robert Rino, a pesar de su voluntad, había declarado la existencia de unos miembros, en la Residencia General en Marruecos, que procuraban cristianizar a los bereberes, impulsados por Roma...etc. Después la revista mencionada, había publicado en el número del 21 de Septiembre, otro artículo que trata el mismo tema. Mientras la Residencia General Francesa en Marruecos, castigaba severamente, bajo el nombre del gobierno marroquí, utilizando todos los medios de tiranía y salvajismo, como vais a ver en los resultados de las informaciones.

La reacción de la gente contra el Dahir, sigue todavía, y los lazos nacionales se refuerzan más aún, así como la conciencia que va creciendo, como demuestra la solidaridad de todos los países islámicos. Tiene usted que saber que los marroquíes se han despertado definitivamente, a causa de esta calamidad; el que no puede hablar, lucha discretamente. 
En la semana pasada, habían liberado casi a ochenta de los detenidos en Fez, y les habían amenazado con azotarles cien veces, con un año de encarcelamiento, si vuelven a oponerse a la labor del sultán...Todavía siguen deteniendo a algunos miembros en Fez y en Rabat. Mientras en las cábilas, la fuerte vigilancia impide la difusión de las informaciones, y hemos conocido por medio de algunos extranjeros, que veinte hombres de los burgueses de la tribu Arhamna (vecina de Marrakech); habían sido ejecutados en un solo día, como castigo por la manifestación que habían realizado contra la cuestión berber iDios nos ayude! De las informaciones de Salé: su pacha había encarcelado a 'Ali Al Haŷ Bubker, el de Málaga, que habíais conocido en Tetuán, a pesar de que tiene nacionalidad española, y los fueros internacionales exigen su persecución por los tribunales civiles, finalmente me había informado uno de sus amigos que estaba en la cárcel en huelga de hambre iDios es potente!

En Ayt Hamu y las regiones de Tafilalet, la situación sigue como siempre, y el gobierno tiene la obligación en aquellas regiones de asegurar la seguridad de los caminos, así que las tribus del Atlas, siguen con su situación de agitación y desorden, pero sin ningún beneficio, y se dice que sus cabecillas están esperando la vuelta del paša Athami Al Glawi, de París, porque les había prometido rectificar el Dahir, lo más pronto posible, de una manera satisfactoria, que aleja toda ambigüedad en lo que toca a la religión. Este volvió de París ayer por la tarde, pasó un día en Tetuán y declaró su disgusto tanto por el fanatismo del visir, Mohamed al Maquari, como por el nefasto Dahir. Su declaración fue hecha en presencia del cónsul de Francia, y en casa de la Residencia General Española iDios es potente y sabe lo oculto de las cosas!

La idea del boicot a las mercancías, había sido publicada en todas partes, su huella parece aún en las tribus bereberes, como Z'ir y Zemur. En Rabat habían construido una sociedad para la fabricación de un "Klbik", que reemplazará el sombrero traído de Francia; así que unos de la gente de Fez, habían trabajado para mejorar los vestidos de los habitantes de la ciudad, esto en lugar de "Al Ŷoj" traído de Europa. Puede que traigan para esto máquinas de tejer, lo que explica un movimiento considerable de boicot económico.

Señor, he pasado nueve días en la Península Ibérica, sobre todo en Granada. Mi estancia allí no fue solamente para ver los monumentos árabes dejados en estos países, por la civilización suprema de nuestros abuelos; sino que he cumplido un trabajo, puedo decir que con éxito, negociando con hombres que disponen de capacidad para construir una fábrica de azúcar. Su centro va a ser en Tetuán, mientras la factoría va a ser, ya en las regiones de Melilla, ya entre Ceuta y Tetuán, y el capital de esta sociedad va a ser 3.000.000 de pesetas españolas; en ella, va a ser igual la participación de los marroquíes y de los españoles. No hemos vuelto de España hasta que hemos arreglado todo con el gobierno, y el ingeniero empezó a trabajar sobre los planes de la factoría, y sus elementos mecánicos necesarios. Y si este proyecto se realiza, para Francia va a ser una calamidad; porque según los censos oficiales, los marroquíes consumen 180 mil toneladas de azúcar anualmente, 90\% de ella se traen de las factorías de Francia, el resto de Bélgica y Holanda. Y lo importante de este proyecto es la existencia de la materia prima, que es la remolacha o las cañas de azúcar. Estamos entonces discutiendo el proyecto con el representante de la economía de la república cubana en España iDios nos ayude! 
He mostrado vuestra carta a mi cuñado que os saluda, y le insistí para que le escribiera al doctor Ŝhbandar ${ }^{3}$, pienso que lo ha hecho. Si el hombre es un laico como pretende, entonces su doctrina le obliga a ocuparse del problema de los bereberes y protestar contra Francia que sigue su laicismo en su política horrible, que contradice sus propios principios.

Pienso que mi hermano Al Haŷ Mohamed, os ha informado de su viaje a El Cairo, acompañado del señor 'Abd Al-Jalek Torres, así en el momento de escribir esta carta, he recibido un telegrama anunciando sus llegadas a El Cairo, con todas las informaciones interiores del país, mi hermano va a daros su dirección en El Cairo, y nos honra estar todos a vuestra disposición.

Con gran respeto os paso el saludo de todos los hermanos y amigos, pidiendo el perdón, si he tardado en responder por los motivos que ya he citado.

‘Abd Salam Bennuna.

\section{Carta no 2}

Loor a Dios:

Tetuán, 27 de Octubre de 1930

Señor y hermano glorioso, Al Emir Šaquib Arsalan iDios el altísimo le proteja!

He mandado a su alteza unas cartas, deseándole que le encontrarán en buen estado de salud, al mismo tiempo, van acompañadas de la valiosa respuesta - de la biblioteca internacional, en Ribat Al Fath (Rabat)- que concierne a los libros históricos deseados por su alteza.

También os he mandado la revista tunecina "Lisan $A s ̌ a$ ' $b$ ", por su artículo que trata el problema berber, como respuesta a lo que ha escrito la revista argelina "Al Naŷah".

Nos habían llegado informaciones del interior ${ }^{4}$, que dicen que habían encarcelado anteriormente a muchos de los nacionalistas en Casablanca, Rabat y Fez; con el fin de terminar con los que se oponían al presidente Doumergue ${ }^{5}$, durante su residencia en Marruecos. Pero después, los habían liberado. Todos los que tienen una conciencia se negaron a participar en la fiesta, y a salir para ver al presidente. En todas partes había muchos guardias, teniendo así mucho cuidado para que el invierno no viera, ni oyera algo que no le gustara. Pero lo que llamó su

\footnotetext{
${ }^{3}$ Abd al-Rahman Shahbandar (1880-1940), nacionalista sirio fue ministro de exteriores del Reino Arabe del Emir Faisal y fundó en 1925 el Partido del Pueblo que desempeñó un papel importante en la revuelta contra el Mandato francés.

${ }^{4}$ El sur de Marruecos ocupado por los franceses.

${ }^{5}$ Gaston Doumergue (1863-1937), Presidente de la República francesa entre 1924 y 1931.
} 
atención, durante su discurso en Casablanca, fueron los aplausos del público al pronunciar el nombre de Lyautey, mientras al pronunciar el de Steeg ${ }^{6}$ y Saint ${ }^{7}$, nadie aplaudió.

Se dice que había empezado la encuesta con Al Maqari, el presidente del tribunal de apelación Mohamed Ben El 'Arbi Al 'Alawi y su consejero francés, y el ministro de justicia, Mohamed Aronda; en lo que concierne al nefasto Dahir, así como las causas de su proclamación. Y finalmente este problema lo trataron en un tribunal privado, a causa de la existencia de unas cartas de las personas mencionadas, en la biblioteca del consejero francés. Pero pienso que si hubiera algo de verdad en esto, los franceses no se atreverían a seguir su política del Dahir, y por el contrario no concederían al salvaje y vil Ibn Al Bagdadi-gobernador de Fez- la legión de honor, por sus vilezas.

Hemos sabido que lo ocurrido en Tafilalet fue provocado por los franceses, que habían querido avanzar en las regiones que no les habían obedecido jamás, por lo que fueron mal recibidos por la gente. Mientras en Juribga, Jenifra, Ayt Ŝagroŝn, Wad Um-Errabi y Awlad 'Amran, están padeciendo las violencias y las manifestaciones de la gente, consecuencias del nefasto Dahir. El ministro de guerra francés había visitado las tribus sometidas a la obediencia del Majzen y había concedido a los cabecillas medallas, pronunciando discursos en sus reuniones, para incitarles a mantener la obediencia a Francia, que es tanto como una obediencia a su soberano, prometiéndoles muchos regalos si aceptaban la paz, etc.

Los periódicos franceses han informado de las felicitaciones del presidente de la República al ministro de guerra por su éxito en la misión que ha cumplido.

Quería mandar a su alteza un ejemplar de un libro escrito en francés, dirigido al Presidente de la República, por lo que ha tardado mi carta un día más. Pero todavía no ha llegado de Fez, y una vez que llegue voy a mandaros este ejemplar.

Haga usted el favor de presentar mis calurosos saludos a los príncipes, 'Adil y Galeb, al mismo tiempo os saludan mis hermanos y mis hijos.

\section{'Abd Asalam Ben Larbi Bennuna}

\section{Carta $\mathrm{n} \div 3$}

Loor a Dios:

Tetuán, 5 de Diciembre de 1930 - El 14 de Raŷab de 1349.

\footnotetext{
${ }^{6}$ Thèodore Steeg (1868-1950), Residente general en Marruecos entre 1925 y 1929 y más tarde Primer ministro y ministro de Colonias de diciembre de 1930 a enero de 1931.

${ }^{7}$ Lucien Saint, sucedió a Steeg como Residente general entre enero de 1929 y septiembre de 1933.
} 
Señor y glorioso Emir, iQué Dios haga perdurar su gloria!

Señor, me ha honrado recibir su carta del 31 de Octubre, un poco después de su llegada. Yo había estado enfermo casi un mes iDios nos ampare! Y se ha cumplido mi restablecimiento en la semana pasada. A pesar de mi enfermedad, no me olvidé de responder a nuestros hermanos en el sur, enviando lo que llegaba de ellos -informaciones y artículos- a mi hermano el Haŷ Mohamed en El Cairo para darlas después al hermano militante Mohib Adin Al Jatib. Este había publicado uno de estos artículos, pero aún quedan tres sin publicar, así como el libro blanco de la gente de Fez, dirigido a Doumergue, Presidente de la República. Le he insistido a este hermano para que traduzca este libro, y lo haga imprimir en las páginas de los periódicos, y en la lengua de la nación "cariñosa".

Estaba esperando con mucha ansiedad los números de "Al Manar" que contienen su elegante respuesta que concierne a la pregunta de Al Glawi. Del artículo publicado en la revista " $A$ I Fath", hemos mandado veinte ejemplares al sur. Mohamed Daud -que os saluda-, había hecho lo mismo con sus amigos.

Respetable señor, he hecho todo lo posible, incitando a la gente para reunir dinero y enviarlo a la comunidad de los estudiantes marroquíes en París, por eso, he escrito más de cien cartas, pero todas las respuestas, habían sido solamente promesas, con excusas de la crisis monetaria, y quejas de la situación económica. Hace 20 días que mandé a los estudiantes un poco de dinero; y hasta aquel entonces, no han respondido para informarnos de su llegada.

Pienso que os he escrito en una carta anterior la respuesta del literato Mohamed Aqali, concerniente a la traducción del libro de la guerra de los moriscos. Me ha prometido enviar unos cuadernos porque había terminado su traducción del español al francés. Puesto que viajaré mañana a Tánger, voy a visitarlo otra vez, para enviar a su gracia lo traducido.

Señor, cuando usted decida visitar España, estoy a su disposición, ya en el mes de Octubre, o antes iDios os ayude y os bendiga!

El proyecto de la factoría de azúcar depende de mi vuelta otra vez a España para ver al delegado que llegará de Cuba a principios de Enero próximo iojalá! Más adelante informará de lo que pasó.

Al mismo tiempo que llegó su carta a mi hijo Daud, me encontraba con la traducción al árabe del artículo indicado por usted en la revista "Atan" que había sido traducido y publicado en Túnez por la revista "Anahda" (renacimiento), en sus números 2348-2346, del 19 y 20 de Ŷumada Azania con título: "Historia de la visita a Marruecos". Finalmente, estamos esperando la llegada de su traducción y la respuesta en la revista "Ašora".

"Anahda" ha publicado esta semana, la traducción al árabe de un artículo de la revista "Monde" parisina, con la firma de Daniel Tiran. Su título: "Francia detenta el poder en Marruecos", su autor, con la ayuda de nuestros hermanos, había criticado la situación de aquel entonces. 
Hace dos días que he recibido su carta del 23 de Noviembre y me ha honrado leerla. No hay que dudar de la solidaridad entre Francia y España contra el islam y los musulmanes, además de los reproches de Francia a España al permitiros entrar en esta región. En los últimos días del mes pasado, tuvo lugar la reunión de $M$. Saint -el residente francés- con M. Jordana ${ }^{8}$-el residente español- en Alcázarquivir, discutiendo de estos asuntos. Pienso que Francia ha logrado convencer a Inglaterra de ayudarla, lo explica un mensaje venido de Fez, que dice: "No envíes el correo inglés, porque ha ocurrido algo, y espero las noticias. Tu amigo". Al asombrarme las noticias, no he enviado ni las cartas venidas de Francia, ni las revistas. No sé lo que haré después. Las conversaciones de Francia con los demás países acerca de este asunto, van a publicarlas en "Atan", el 4 de Noviembre iDios es potente!

Señor, gracias por habernos informado de la carta del rey Ibn Sa'ud, al presidente de la República francesa, deseo que hagan lo mismo, con Al Imam Yahya, Nadir Jany Faysal.

Las noticias de las tribus del sur no llegaron a las ciudades que estaban muy controladas. Pero las noticias que sabemos, nos llegan mediante los españoles. $Y$ a pesar de que ambos se cubren, la realidad es que las tribus se rebelaron contra el colonialismo. Y el día 11 de Noviembre, tuvo lugar, una guerra en las fronteras de las tribus de Hamu y Ayt Mograd, lo que les obligó a utilizar todo tipo de aviones que tenían aquí en Marruecos, y sin esto hubieran fracasado. Al día siguiente, tuvo lugar también, un enfrentamiento en las regiones de Ayt Ishaq y Ayt Sajmón. En general habían hecho desgraciado el día que Francia llamaba "La fiesta de la gloria".

Respetable señor, buena opinión, es la de construir una sociedad con un capital de 45 mil francos suizos, para la revista "La nation arabe", porque lo explicado en sus cartas, no se puede aguantar. Había usted hecho lo posible para soportarlo iDios os ayude!, los hermanos tienen que participar en este glorioso ŷihad, con lo que tienen de dinero. Pienso que por lo menos existieron 40 personas que darán cada uno mil francos suizos para cumplir con esta importante misión, sobre todo, si el pago era a plazo de 10 meses; por ejemplo: las acciones de la sociedad son 400, el participante pagará 1000 francos por cada acción, en un mes. Voy a ser el primer participante con mil francos suizos iDios nos ayude!

Ha llegado la lista de los participantes, y he escrito a la mayoría, obligándoles a cumplir con este deber. Cuando llegue algo, voy a mandarlo a su excelencia, el señor Ihsan Al Ŷabiri, al que saludo calurosamente.

La cuestión de la construcción de una casa al estilo de las de Andalucía en Sofar.

A mi parecer tiene que ser independiente de las fotos que me ha mandado usted.

Deseo que salude usted de mi parte a los dos gloriosos príncipes, Al Mawla 'Adil y Al Mawla Galeb, y os mando el saludo de todos los parientes, sobre todo de Mohamed al Masmodi y Ašayj Ni'mat Alah Adahdah, el literato Habib Abu Sulayman, y finalmente, el señor cónsul de España que pregunta siempre por usted.

\footnotetext{
8 Francisco Gómez-Jordana Souza (1876-1944) fue Alto Comisario de la zona española del protectorado entre septiembre de 1928 y abril de 1931.
} 


\section{Carta no 4}

Un saludo de 'Abd Salam Bennuna.

\section{Loor a Dios:}

Tetuán, 10 de Diciembre de 1930

Glorioso señor, y respetable Emir Šaquib Arsalan, ¡Dios el altísimo le proteja y bendiga su vida!

Mawlay, he enviado a su gracia una carta en esta semana, pero no he terminado con unos temas como he señalado, lo importante, es que al ver las fotos de su casa en Sofar -las he devuelto en la carta anterior-. Tenía la obligación de aconsejaros terminar esta casa a la manera europea, porque su forma geométrica, no corresponde con la construcción por arriba de una casa árabe andaluza. Lo justo señor, es que esperaba la mejora de las circunstancias, para construir esta casa desde el principio. Así he empezado a dibujarla y hacer un presupuesto para su construcción, con el azulejo de Fez o de Tetuán, y un techo de madera tallada y coloreada. Ya que existe agua corriente, elevada de la superficie de la tierra en que va a construirse la casa, voy a incluir en el plano fuente con surtidor y piscina, como todas las casas árabes andaluzas. Al ver en las fotos sólo piedras talladas, quiero que me informe usted, si existen en Sofar ladrillos de barro quemado. $Y$ si puede usted dar aclaraciones sobre las siguientes cosas, el presupuesto va a ser más o menos justo:

- Ladrillo: longitud...altura...precio de mil en francos.

- Las piedras de construcción, ¿cuántos para el metro cúbico en F.?

- Cal viva, ¿cuántos para el metro cúbico en Francos?

- La madera de cedro, su longitud, anchura y su precio en Francos.

Pero las demás materias de construcción, como el hierro, el cemento, el yeso,...etc.; pienso que tienen el mismo valor.

He enviado a su alteza unos dibujos de azulejo, y voy a mandaros unas partes dentro de una caja en el correo, este azulejo es fabricado en Fez, se llama "Grabado" porque es fabricado en partes cuadradas de $0,10 \times 0,10$, después lo corta el grabador con el buril. Mientras el que se fabrica en Tetuán, su barro es más duro, lo mismo para el esmalte, por eso no se acepta que los artesanos graben según su voluntad.

Hubiera sido necesario cortado antes de quemarlo. De todas maneras usted, va a ver la diferencia entre los dos. El hecho de mandar grabadores de aquí es fácil, porque existe dentro de ellos, los que lo quieren sinceramente. Al decidir su gracia, vamos a indicaros el pago, y lo necesario para el viaje a Marsella y después a Beirut iDios nos ayude! 
Señor, de su respuesta a mi hijo Daud y la carta mía, he comprendido su buen comportamiento con el doctor Šahbandar, pero siento mucho el mal comportamiento de este último con usted, que había hecho lo posible para cambiarle en un ser bueno, pero en vano porque es Dios quien orienta a los seres al buen camino.

He recibido la respuesta del erudito, señor Ŷa'far Anasiri, en lo que concierne a los libros que estamos buscando para su gracia, este había dicho que no los tiene en su biblioteca, pero el erudito e historiador, señor Mohamed Ben 'Ali Adukali, los había buscado y le había respondido diciendo: "estos mismos libros, los había buscado el padre Martanios, el español que se preocupa por la biblioteca del Escorial, durante su estancia en Salé. Hemos respondido al padre mencionado "Atarij Al Kabir", de Ibn Hayan, existe solamente en la biblioteca de Ibn Basam, lo mismo para, EI bayan Al Magreb y Nofhatib, así en la biblioteca del Majzen (gobierno), existen dos tomos: el primero y el quinto, uno en la biblioteca de Mequínez y el otro en la de Fez. Esto hasta la época de Mulay Hafid, pero no sabemos lo que habían sido después. En el Escorial, hay un cuarto tomo de los libros de Mawlay Zaydan Asa'di. En España están editando el tomo de Tarij Ibn Hayan mencionado, así que los largos artículos de Nafh Atib, Tarij Ibn Hayan, en lo que concierne a Córdoba, y lo que se le añade de las noticias de sus reyes y de sus ministros, todo esto en los tres tomos que existían en la biblioteca de Al Mansor Asa'di.

No cabe duda de que Al Maqari disponía de estos tesoros también. Este glorioso Tarij, al tener un gran volumen, ninguno de los reyes andalusíes había podido reunirlo en su biblioteca.

Mientras la historia de Córdoba de Arazi, existe uno de sus tomos en el Escorial, lo había visto el ministro Algasani, en el año 1102 de la hégira, y en su visita, había copiado uno de sus artículos.

Mientras la historia de 'Arib Ben Sa'id el Cordobés, se la conoce por unos relatos copiados en el Bayan de Ibn 'Adra.

Además de la historia de Mallorca de Al Majzuni, está escrita en el libro de literatura e historia del juez de Salé y Mequínez, que es el gran erudito y el excelente autor, Ahmed Ben Omaya Al Majzuni, el valenciano lo había editado con el seudónimo del presidente Abu 'Otman Aqoraši.

Señor, en la semana pasada la policía secreta "La sureté" -en Tánger y en Tetuán- habían empezado la búsqueda del Emir Michel Lotf Alah, según unos rumores, había llegado a Ceuta por una misión política. Todavía siguen las investigaciones ¿No sé que opina usted?

En la entrevista tunecina "Lisan Aša' $b$ " he leído unas noticias importantes sobre la guerra de Trípoli, y he querido informaros con este artículo. Mientras la revista francesa "Je suis partout" ${ }^{\prime \prime}$, no cabe duda que había usted leído su primer número publicado el 29 de Noviembre de 1930, bajo título: “El desorden general en África del norte y en la Indochina”.

\footnotetext{
${ }^{9}$ Periódico francés publicado por Arthème Fayard entre 1930 y 1944 . Si bien inicialmente no definió su ideología, poco a poco iría deslizándose hacia posiciones cercanas al fascismo.
} 
Deseo que se traduzca este artículo, y que se publique en los periódicos árabes.

Deseo que pase usted mi saludo a los gloriosos príncipes. Os paso también el saludo de los hermanos y amigos, sobre todo a mi hijo Daud que estaba en Fez, vigilando las situaciones y haciendo entrevistas con los fieles hombres nacionalistas. Al volver va a escribiros una carta que trata el tema.

Tengo aquí la suma de dos participaciones en la revista "La nation arabe", estoy esperando unas respuestas, para mandar lo que lograba tener de participaciones, a su alteza el respetable señor Ihsan Al Ŷabiri, que os saludaba calurosamente.

Un saludo de 'Abd Salam Ben Al Haŷ Al ‘Arbi Bennuna.

\section{Carta no 5}

Loor a Dios. Tetuán, Enero de 1931.

Su gracia el glorioso, señor Šaquib Arsalan ¡Dios el altísimo le proteja!

He dirigido a su gracia una breve respuesta en el momento en que he recibido su carta que espero que llegaría, porque está acompañada de unos artículos escritos en francés.

Señor, os he informado de la llegada en esta región, de la revista "Al Fath" (la conquista), y otros periódicos y revistas. También informaciones sobre la manera de su llegada a algunas ciudades de la región del sur. En los años pasados, mi hijo Daud había pedido las revistas para venderlas por su cuenta, pero nadie las ha comprado, lo que le había impulsado a distribuirlas gratis. Pero había esperado con un poco de paciencia hasta que la gente se volviera consciente y se interesara por saber las noticias. Desde entonces las revistas se venden todas, sobre todo la revista "Al Fath" y "Al masa"' (la tarde), lo que explica la existencia de una preocupación por la situación del mundo árabe, y sobre todo los países islámicos. Existen algunos que habían participado en la revista "Hadramawt".

Al existir que unos hablan francés, pienso que participaron en la revista "La nation arabe", por la importancia de sus temas, y sus servicios para toda la nación islámica. Estoy esperando la ocasión para ir al sur, intentar reunir unas participaciones y enviarlo mediante el correo inglés ¡Dios nos ayude!

La crisis económica se agudiza demasiado en estas regiones, porque Francia no hizo más que saquear las riquezas de la gente, con los enormes impuestos, para vengarse de ellos. 
Según las noticias venidas de diversos países, estamos esperando una sublevación en la próxima primavera, deseando que participen en ella unas tribus iDios nos ayude! Tengo grandes esperanzas en la toma de conciencia de las naciones musulmanas.

Actualmente, la atención de la gente se orienta en cambiar unos vestidos fabricados en Europa por vestidos nacionales, a pesar de la necesidad de aportación de las materias primas.

Lo indicado por usted, que concierne a la ayuda de nuestros hermanos, estudiantes en París. Como había usted dicho, es "un proyecto santo". También es la obligación de cada miembro de los marroquíes. Estoy seguro de que la venida del Al Fasi y Balafreŷ en este mes, va a tener consecuencias.

Desde hace casi dos semanas, he enviado una larga carta explicando el problema marroquí al presidente del congreso islámico en Londres, además he enviado un ejemplar de esta carta, a mi hermano Al Haŷ Mohamed en El Cairo, para que lo publique en las revistas, o en un edicto especial, con las demás declaraciones.

He recibido con mucha alegría, los diez ejemplares del libro "Limada Ta'ajara Al Muslimun" (¿Por qué tardaron los musulmanes?), que su gracia me había mandado. Deseo que escriba usted al erudito del islam -profesor respetable-, el señor Rašid Rida, para que nos mande unos cien ejemplares para venderlos y darle su dinero. ¡Qué Dios os proteja!

Deseo que usted no haga reproches al literato Aqalí, que os respeta. Ha sido perseguido por el gobierno. A pesar de esto, ha traducido unos capítulos del español al francés que voy a mandaros después. Todo su trabajo lo había cumplido en casa de su amigo, porque la suya estaba amenazada por la inspección en cualquier momento.

Señor, había usted hecho bien de pedir al general Karamon, la lista de lo necesario para la factoría de azúcar. Por favor, no olvide usted este proyecto, porque es muy útil para nosotros, sea que la lista está escrita en alemán, o en francés, tenemos aquí a amigos que van a traducir; esto para no fiarnos solamente en lo que dicen los españoles.

Es muy triste la no intervención de Ibn Saúd, y los demás reyes del islam, en el problema berber. Nos quedan solamente esperanzas en el boicot a las mercancías, como había usted dicho.

Dios sólo sabe, el amor que reservo a su fiel hijo, y al príncipe 'Adil, después de saludarles, deseando que Dios nos reúna en un agradable momento, si no fuera por los grandes gastos de mis hijos en el extranjero, visitaría Suiza para encontraros.

El doctor Šahbandar no ha respondido a mi cuñado Daud sobre su conocida petición, y es lo que habíamos creído todos...Pero mi hermano Al Haŷ Mohamed lo encontró en casa de Ahmed Zakri Baša, y trabó amistad con él. El doctor había mostrado gran interés al problema de la eliminación de la lengua árabe

Pero la cuestión religiosa no tiene ninguna importancia para él. Por eso mi hermano ha dicho: "me han reservado una buena acogida, y se ha puesto muy alegre al informarle que los jóvenes marroquíes -encarcelados a causa del problema nacional- estaban contando uno de sus 
poemas "oscuridad de la coral". Sabrá usted que el doctor es uno de los cabecillas de Siria, y es un enemigo del querido Emir. Hay una diferencia entre los dos, la bondad del Emir, su sabiduría y su gloriosa personalidad que se nota desde la primera vista. Mientras el doctor, es astuto y grosero, y partidario de la guerra". Con esto acabó mi hermano.

Con su carta, he encontrado la de Ŷa'afar Anāsiri. Doy las gracias a Dios que me ha incitado a copiaros lo importante de esta carta.

He escrito a las grandes bibliotecas de España, preguntando sobre los libros de la Historia de Mallorca. Las respuestas voy a enviarlas traducidas después. Otra vez intentaré escribir al Mawla Zaydān unas indicaciones que conciernen a este proyecto.

No conozco a Michel Lotf Alah, pero he oído que había dado graciosamente una tierra situada en el bulevar Alfuŷala, para que se construya una iglesia ortodoxa. ¿No sé lo que esperaban los musulmanes después de esta situación?. Durante la guerra europea, su hermano Habib había sido desterrado a España. Nos hemos encontrado en Madrid, y me ha visitado en Tetuán. Ha constatado que es un hombre orgulloso que no sirve para los árabes. Al regresar a $\mathrm{El}$ Cairo y a Italia, me ha escrito, enviándome muchas revistas, como "Sarquis", o las que describen el lujo y las fiestas que se hacen en su casa.

Esto es lo que sabía yo de la familia Lotf Alah.

No cabe duda que su profecía acerca de Turquía, resulta cierta iDios mediante!

Y va a volverse país islámico, más que antes, a pesar de las repercusiones de Mustafa Kamal y de su partido.

¡Deseo que tenga usted medios mejores para luchar a favor de la cuestión relacionada con los alemanes, que terminará como quiere usted!

Estoy esperando señor, con mucha ansiedad, buenas noticias acerca de la alianza deseada por los dos reyes y el Imam.

Con ocasión de su viaje a Berlín, os informo de mi correspondencia con el partido existente allí, sabe usted sin duda unos de sus miembros, os he mandado una explicación que trata este tema. Haga usted el favor de informarnos sobre la verdad de esta reunión, y las consecuencias de sus trabajos.

Os paso el saludo de todos los hermanos y amigos, sobre todo Ašayj Ni'mat Alah Adahdah y el señor Habib Ben Sulaymān.

Un saludo de 'Abd Salam Ben Larbi Bennuna. 


\section{Carta n으}

Loor a Dios.

Tetuán, el 4 de Šawal de 1349 / 22 de Febrero de 1931.

Su gracia, glorioso y respetable Emir, señor Šaquib Arsalan ¡Dios altísimo le proteja!

Me ha honrado recibir su carta del 13 de Febrero pasado, dando gracias a Dios por vuestra buena salud, así que el encuentro con vuestra familia. después.

Para la carta de su amigo -el hijo del general Karamon, el alemán- la respuesta va a ser

Los cuatro ejemplares de su carta: “¿Por qué... y por qué... ?” Os he dicho antes que habían Ilegado, aquí tengo la respuesta de Ibn Zaydān que dice: "He recibido con alegría, la carta del querido hermano, mis gracias para ustedes, así como mi saludo". He dirigido después esta carta a mi hermano Al Haŷ Mohamed, porque trataba en general la respuesta al erudito el islam -Ašayj Rašid Rida- que no había respondido al Mawla Zaydān cuando este último le había regalado dos tomos de su libro "Al Ithaf". Esto es debido a unos rumores que había escuchado, y que dicen que Ibn Zaydān es cómplice del colonialismo. El hermano Balafreŷ no me ha respondido sobre el ejemplar que le he mandado. Estoy esperando los cien ejemplares para venderlos, como me había usted indicado, van a ser distribuidos mediante el correo inglés. Mientras los diez ejemplares, regalados por usted, voy distribuyéndolos a quienes me indicó usted. Entre ellos figura Ašayj 'Abd Lhadi Slawi, que se quejaba de no haberle escrito, me ha preguntado sobre la causa, le he respondido que usted tiene muchas obligaciones.

Siento gran pena por la venta de su finca, pero como había usted dicho, esto es resultado de las circunstancias, y de la crisis económica general, en este año ¡Dios es potente!

Me había alegrado, la ayuda del rey Faysāl a la revista, así como la del Imam Yahya e Ibn Sa'ud ¡Dios bendiga sus vidas!. Porque esta revista importa a todos los reyes del Islam.

No me acuerdo en qué revista he leído que el rey Faysāl había nombrado un embajador, enviándole al Hiŷaz, para firmar una alianza con el rey Ibn Sa'ud.

¿Es verdad esto? ¿Vuestro precioso trabajo había tenido como resultado este éxito? Infórmeme de la verdad y gracias.

Os pido pasar mi caluroso saludo al Mawla Gāleb, y a su alteza el respetable señor Ihsan Al Ŷabiri, y al Mawla 'Adil iDios le proteja!. Haga usted el favor de decir al hermano Al Ŷabiri que quería yo presentar una ayuda para la manutención de la revista, porque siento que es una obligación, ya que esta revista se preocupa por la lucha a favor de las naciones árabes e islámicas.

Ayer por la tarde, asistimos al nacimiento de mi noveno hijo, al que doy el nombre de Mohamed 'Ali. 
Me había llegado una carta de mi hermano Al Haŷ Mohamed, en la que me informaba de que habían formado un grupo de seis estudiantes marroquíes que son: Mohamed Bennuna, Al Hasan Bu'ayad, Mohamed Atanŷi, 'Abd Lkader Ariyahi, Atayb Asebti y Al 'Arbi Berada. Se habían dirigido al Mawla Škat 'Ali para darle el pésame, al morir su hermano Al Mawla 'Ali ique en paz descanse! Me había hablado también de la larga discusión del grupo con Šawkat, en casa de 'Abd Lhamid Bik, y en la que declaraba lo siguiente: "os prometió hacer la propaganda para la cuestión marroquí, entre los musulmanes de India, que todos están a mi disposición. Y como hizo la propaganda contra las mercancías inglesas, lo mismo voy haciéndolo contra las mercancías francesas. Voy tratando este problema en cada reunión, en cada país musulmán, para hacer comprender a Francia que el mundo Mahometano jamás perdonará la pérdida de sus tierras. Después hablaba de su trabajo, para que todos los gloriosos del Islam en general, y particularmente los de India, presenten una protesta oficial, mediante la unión de las naciones. Francia tendrá que terminar su persecución, sino irán formando él y la unión de los jóvenes musulmanes, un grupo encabezado por su gracia el Emir Šaquib Arsalan. Que se dirigirán a Marruecos para ver la situación. Después presentarían una conclusión final". Otra vez le había visitado mi hermano en el centro de la unión de los jóvenes musulmanes, para explicarle en extenso la cuestión bereber marroquí. Deseamos la ayuda de Dios, para que existiera una solidaridad entre las naciones musulmanas. Además de todo esto, mi hijo Atayb me había informado que Al Mawla Šawkat, visitó Nablus, donde le habían reservado buena acogida, en casa de la unión de los jóvenes musulmanes. Mi hijo había pronunciado un discurso en nombre del "Magreb Al Aqsa".

Os paso el saludo de mi hijo Daud y de Ašayj Al Masmodi, y los demás hermanos.

Un saludo de 'Abd Asalam Bennuna.

\section{Carta $\mathrm{n}$ - 7}

Loor a Dios.

Tetuán 18 de Šawal 1349 / 8 de Marzo de 1931.

El glorioso señor Al Mawla Šaquib Arsalan, ¡Dios altísimo le proteja!

He recibido la carta de su gracia del 2 y 9 de Šawal que corresponde al 1 de Marzo pasado. Estaba esperando la llegada de su carta. ¿Por qué...y por qué...?. Pero al no llegar, he preferido responderos.

Todavía no he leído la palabra "Bennuna" en "Taŷ Al 'Arus", a pesar de que lo tenía en mi biblioteca, gracias.

Señor todo lo que puedo deciros sobre el buen trabajo que concierne a sus finanzas, lo mismo lo había dicho él de la Meca, y había usted reconocido que él tiene razón. 
Deseamos que sea pasajera esta crisis para la nación árabe, contra los países europeos, porque casi todos los países musulmanes están arruinados.

Estamos teniendo el problema de la suspensión de la revista "La nation arabe", de Argel. Verdaderamente señor, es muy difícil dirigir la revista en estas circunstancias, y con los precios de las bibliotecas. A mi parecer, lo mejor es que dirijamos los números de los participantes en Argel, a sus amigos en Túnez. Os pido tratar el proyecto con uno de sus amigos allí. Mientras los números de Marruecos, os prometió enviarlos a los nombrados por usted, sin gastos de la administración. Pienso que os he informado que tenía $24 \mathrm{~F}$. Suecos, esto menos la participación de mi hermano Al Haŷ Mohamed y del señor 'Abd Alah Guenun que reside en Tánger.

He tardado en dirigiros la suma mencionada, esperando que llegarán otras participaciones, que unos hermanos de Fez me habían prometido.

Deseo que el proyecto de su casa en Berlín terminará como usted quiera.

Estoy enterado de lo desarrollado entre usted y el joven Al Homama, en Berlín. Ignoro yo totalmente quien es éste. Pero los amigos del Emir Mohamed Ben 'Abdelkrim me van aclarando este tema. En lo que concierne Ahmed Hasan Matar, tengo la misma opinión que usted, sobre su persona.

No me acuerdo si he preguntado sobre Munir Alabaydi, gracias por lo que me había usted indicado. Mientras Šahbandar, sabía yo antes, que era un cobarde al leer lo escrito en "Ašora" por Mawla 'Adel.

Gracias por haberme felicitado por el éxito de mis hijos.

Estaba en Tánger, hace unos días, allí informaba a Akal'i -que os saludaba- de la llegada de los cuadernos a su alteza. Después me he encontrado con Mohamed Al Fasi, que acaba de llegar del sur, dirigiéndose a París, donde está terminando sus estudios. Me había contado lo de la persecución en Fez. Estaba acompañado por Al Meki Anasiri Aribați.

Había escrito al interior y a El Cairo también, deseando que se organicen unas manifestaciones pacíficas en el 16 de Marzo rememorando así el día del nefasto Dahir. He pedido a nuestros hombres de El Cairo, que discutan este asunto con el profesor 'Abd Lhamid Bik Sa'id.

El artículo del cual os he hablado anteriormente, había llegado de Manchester, en numerosos paquetes. Al distribuirlos, hemos cambiado de manera, es decir que hemos dirigido un gran número de ejemplares a todas las ciudades y en un solo día. Todo esto para provocar un desorden al gobierno que va a creer que se trata de un fuerte partido en cada ciudad.

En la segunda carta, usted hablaba del intento de Francia para anular el Dahir berber. Esto puede ser debido a la discusión de Šawkat con el delegado francés en Siria, M. Manisron. Había dirigido las cartas del llamamiento a 'Allal El Fasi y a sus amigos, para animarles y hacerles comprender que todavía en el exterior siguen preocupándose por el caso berber. 
"El boicot a las mercancías extranjeras" una vez que la gente de Fez empezaba a tejer sus vestidos, el número de los telares había llegado a centenares en 35 fábricas. Por eso el gobierno mandaba que quien se ponga los nuevos vestidos -como lucha económica-, va a ser castigado severamente, y al reprochar a los hombres del gobierno, su actuación, se disculpan diciendo que al contrario, ellos animan y llaman al desarrollo de las construcciones nacionales, la prueba es que habían construido una escuela para la artesanía, etc...

Había usted preguntado si existe una fábrica de cemento en Tetuán. Existe solamente en Casablanca, y pertenece a unos franceses, sus fabricaciones no son buenas. Mientras la fábrica construida en Damasco, me había dicho mi hijo que tenía mucha importancia. Lo mismo pasó con la fábrica de "Al Ŷoj".

Con el caso de la fábrica de azúcar, estoy esperando la llegada de un ingeniero amigo mío, para responderos.

Deseamos que llegue usted a una buena solución, en lo que concierne la alianza árabe, y Dios favorece vuestro éxito frente a los dos partidos de oposición. Mientras la vuelta de Aman Alah al trono de los Afganos, pienso que es imposible, ya que el reciente rey, parece muy justo y piadoso.

Me ha extrañado el hecho de que Al Mehdi Lamnabhi no os había respondido.

El libro llegado de Córdoba, Boletín de la Real Academia, contiene muchas cosas importantes, ignoradas por los historiadores árabes, como estas páginas -de 103 a 141-, que os regala el cónsul español, Isidro de las Cajigas. El libro merece la pena traducirlo al árabe. Hay otro libro con título: Páginas turbias de la historia de España que ahora se ponen en claro, que traduce la enemistad de los españoles a los árabes. Después de la traducción del primer libro, voy traduciendo del segundo, todo lo que trata la historia de los árabes.

Ibn Gibrit regresó a Marruecos y empezó a pronunciar sus conferencias de herejía en Ribat Al Fath.

Estamos esperando su artículo "Un país puesto en una caja" etc...No sé en que revista lo había usted publicado.

Os paso el saludo de mi hijo Daud, del hermano Al Masmodi, y de todos mis hijos.

Un saludo de 'Abd Salam Bennuna. 


\section{Carta no 8}

Loor a Dios.

Tetuán el 25 de Šawal 1349 / 15 de Marzo de 1931

El respetable y glorioso Emir, Šaquib Arsalan ¡Dios altísimo le proteja!

He recibido su honorable carta del 6 de Marzo pasado, en la que me felicita usted del nacimiento de mi hijo. Gracias por todos los consejos.

Había llegado su carta para Ašayj 'Abd Lhadi Slawi. La he mandado con un ejemplar de la carta ¿Por qué...?, a este último. Estoy esperando su respuesta.

El autor del libro Al Ithaf, merece toda importancia, por sus estudios e investigaciones en los asuntos históricos. El tercer tomo que trata la vida de Mawlay Isma'il, estaban editándolo.

Señor no tengo esperanzas en la ayuda de Al Haŷ 'Omar Atazi, -el gran rico del cual me había usted hablado-. A pesar de todo esto, voy a escribirle. Me extrañaba mucho el hecho de que este señor no tiene herederos, sus hermanos son ricos y está enfermo.

Me alegra mucho, su impotencia por la alianza árabe, así que por la alianza político militar entre su majestad Ibn Sa'ud, el rey Faysal y el Imam Yahya. Pero aquí en Marruecos consideran esta alianza como un complot inglés.

Me interesó mucho el acuerdo firmado en la India, lo que representa una calamidad para Francia, si todas sus colonias hicieran lo mismo.

Hace tres días que he recibido mediante el correo, 3 paquetes que contienen 98 ejemplares del libro ¿Por qué...? Y en un solo día he vendido 88 ejemplares, a 2 pesetas cada uno, la suma es 176,00.

He recibido una carta del 10 de Marzo, acompañada del segundo número, del segundo año, de la revista "La acción árabe", al leer la tabla de materias, me había encontrado con importantes estudios.

Por favor, al escribir a Rašid Reḍa, infórmele de la llegada de los 98 ejemplares, para que se tranquilice.

Voy a escribir a Mawlay 'Abd Rahman Ben Zaydun, para hablarle de los artículos editados por usted.

Pasa usted mi saludo al Mawla 'Adil y Galeb, y al señor Ihsan Bik Al Ŷabiri, os paso también el saludo de mi hijo Daud y todos mis hijos. 
Un saludo del fiel, 'Abd Salam Bennuna.

\section{VII.9.- El texto de la carta no 9}

Loor a Dios.

Tetuán 9 de Dilqui' da de 1349 / 28 de Marzo de 1931.

Glorioso señor ¡Dios le proteja!

Nuestro querido amigo Mohamed Ben Lhasan Al Wazani, había decidido dirigirse a Lausana en el verano próximo, para preparar su doctorado. Por eso quería unas informaciones sobre el modo de vivir en este país, estoy esperando de usted una respuesta acerca de este tema, y aquí está la carta de Al Wazani. Además os mando lo llegado de Fez, de artículos escritos en francés y también la respuesta del señor Al Menebhi que os saludaba.

Estamos haciendo todo lo posible para preparar a la gente para manifestarse pacíficamente, el día 16 de Mayo próximo - día del nefasto Dahịir-con esto se van distribuyendo numerosas octavillas a todos los países, un día antes de la cita, pero todo esto necesita un poco de discreción para que la administración no se oponga tomando precauciones antes del acontecimiento. ¡Dios nos ayude!

Pasa mi saludo a los dos príncipes, ‘Adil y Galeb iDios les bendice!

Un saludo de 'Abd Salam Bennuna.

\section{VII.10.- El texto de la carta no 10}

Loor a Dios.

Tetuán el 13 de Dilhiŷa de 1349 / 2 de Mayo de 1931.

Glorioso señor, su alteza el Emir Šaquib Arsalan iDios le proteja!

Mi hijo Daud me ha dado su carta con unas partes de periódicos que relatan los acontecimientos del establecimiento de la república. Pero antes, os he mandado una carta con lo ocurrido.

Pienso que la república española había firmado un acuerdo con el catalán, por eso, estos últimos habían retardado sus reclamaciones en el interior de Cataluña, hasta después de la apertura del parlamento, el 21 de Junio próximo.

El ministro de asuntos exteriores, el señor Laroch, había negado lo escrito por los periódicos franceses, de que la república española abandonará sus derechos en la zona norte de Marruecos. 
Un redactor había preguntado al presidente de la república provisional-Alcalá Zamora- su opinión sobre lo que concierne a la zona del protectorado español en Marruecos, que anteriormente había declarado la necesidad de abandonarla. Este había respondido que esto, había sido su opinión, al infringir Francia la alianza de 1904, cambiando las fronteras de esta zona, de "Wadi Mehdia, Sebu, Warga a Helwia", y separándonos en Wadi Lukus, cerca de Al Kasr Lkabir. Pero hoy, al tener España todas las posibilidades, va reclamando sus derechos en esta zona, porque el gobierno no tenía interés en abandonar sus grandes derechos en el norte de África.

No tengo grandes esperanzas de que van a darnos la independencia interior. Pero con trabajo bien organizado creo que vamos realizando todos nuestros deseos.

Había llegado de París Ahmed Balafreŷ, por eso he viajado a Ceuta para llevarlo con si coche. En mi cama escribimos una agenda de reivindicaciones, para presentarla al gobierno. El viaje tenemos que pagarlo nosotros.

Pero después, me informaron de que el ministro Ibn 'Azuz, había detenido la agenda. Por eso he tardado en responderos.

El 3 de Mayo: regresó Ahmed de Ceuta para discutir otra vez el problema, y la mayoría decidió pedir la carta a Ibn 'Azuz.

Pero si rechaza presentarla, escribiremos otra agenda.

El 4 de Mayo: viajó a París. A las diez por la mañana, se dirigió Athami Lwazani al ministro para llevar la agenda, pero en vano, lo que dio lugar a una gran manifestación de todos los obreros que pedían la igualdad con los obreros españoles, levantando una bandera roja, en la que habían escrito: "hay un solo Dios, y Mahoma es su profeta". Los manifestantes se dirigieron al tribunal y después a la Residencia General, donde insultaron a Ibn 'Azuz. El residente general ordenaba la ley marcial, lo que dio lugar a un enfrentamiento entre los soldados y los manifestantes, que terminó con 40 heridos, entre ellos hubo dos comandantes, 2 capitanes, así como un teniente y la muerte de un soldado. Pero por la tarde arrestaron a unos treinta hombres, entre los que figuran, 'Abd Lakrim Daud, el hermano de mi hijo Mohamed Daud y ‘Abd Latif Gaylān.

Fue Athami Lwazani quien ha podido alejar los manifestantes de la puerta de la Residencia General, prometiéndoles una reunión en la mezquita, el día siguiente.

Daud acudió al coronel para liberar a su hermano, y a Gaylān. A las diez de la mañana, llenaron la gran mezquita y Daud pronunció un discurso, para tranquilizarles y hacerles comprender que deben reivindicar pacíficamente sus derechos ante el residente general, este último les prometió igualdad con los demás obreros, tanto en las horas de trabajo, como en los salarios.

Ibn 'Azuz ordenó al Wazani visitar al alto comisario y discutir con él esta agenda de reivindicaciones. 
Yo pensaba que este último tenía la idea de retardar esta agenda y suspender las elecciones del consejo de estado. De todas maneras intentaré viajar a Madrid, en estos días.

He recibido su carta del 26 de Abril, en presencia de Ahmed quien la leyó. Los dos agradecemos vuestros buenos actos iDios os ayude!

Os he dicho anteriormente, que he recibido el periódico "Al Fath", también "La unión árabe". Mi hermano me ha enviado casi veinte revistas de su artículo sobre Trípoli, que he distribuido finalmente en Marruecos. También me ha enviado el número 322 de "Ašora".

"La unión de los jóvenes" ha cesado de protestarse contra Italia, como había usted señalado.

Italia no permitía la entrada del grupo, sobre todo encabezado por usted, para investigar lo ocurrido en Trípoli.

Mi hermano Al Mojtar, me ha enviado una carta de Sevilla, que trata el caso del cambio de régimen en España, pidiéndonos presentar una agenda de reivindicaciones. Por eso vamos a trabajar, para no perder esta ocasión iDios nos ayude!

Estoy esperando la llegada de una carta de Rašid Reda.

Un saludo de 'Abd Salam Bennuna.

\section{VII.11.- El texto de la carta no 11}

Loor a Dios.

Tetuán el 12 de Rabi' de 1350 / 28 de Julio de 1931.

Respetable Emir ¡Dios el altísimo le proteja!

Hoy mi hijo Daud que os saluda, me ha informado de la llegada de dos cartas de usted, del libro ¿Por qué...? Con la lista de los nombres de los participantes en la revista "La nación árabe".

Después de haber tardado en responderos, por las causas ya dichas en mi carta de 8 páginas del 9 de Julio pasado, os he informado de la llegada de unos ciento cincuenta ejemplares del libro ¿Por qué...?. Cincuenta de los cuales habían sido distribuidos en el interior, a pesar de la vigilancia de Francia. Me ha asombrado Rašid Reda quien temió que no llegaran estos ejemplares. El dinero voy a mandárselo esta semana, para tranquilizarle.

En la semana pasada, regresaron, mi hermano Al Haŷ Mohamed, y mis hijos, Atayb y El Mehdi, que os saluda, todos han aprobado sus exámenes. 
Señor, estamos en guerra contra la prensa francesa. Lo escrito últimamente por la revista Le peuple de Tanger, fue copiado en otras revistas españoles el 23 de Julio: "El partido de oposición en Tetuán, es el partido de los nacionalistas, dirigido por Bennuna, cabecilla del movimiento "Panislamismo", que obedecía a las órdenes de Šaquib Arsalan, el hombre que recibe dinero de un doctor alemán en Berlín, el mismo hombre que había sido desterrado de Tánger, por orden del residente general francés, hace unos pocos meses".

Estoy buscando este número para enviárselo. No cabe duda que de estos artículos impresionaban a los españoles, además de los gastos y la pérdida de tiempo causados por esta guerra.

Nuestra casa ha sido amenazada por la inspección, según las órdenes, pero hoy reina la tranquilidad, al ser nombrado como presidente de la policía secreta, uno de nuestros fieles amigos.
Mi saludo al Mawla Galeb ¡Dios bendiga su vida!
Un saludo de 'Abd Salam Ben Larbi Bennuna.

\section{VII.12.- El texto de la carta no 12}

Loor a Dios.

Tetuán el 10 de Raŷab de 1350 / 21 de Noviembre de 1931.

\section{Glorioso señor ¡Dios altísimo le proteja!}

He recibido su carta del 5 de Noviembre, al regresar de Madrid, donde pasé unos días, arreglando la cuestión de la red de emisoras, para la electricidad en Tetuán, con el nombre de "Sociedad de unión artesanal Marroquí-Española". El día 11 firmé el acuerdo con la sociedad alemana "Brinkaman", por la suma de 440.000 F. Suizos en oro. Las circunstancias me han prometido visitaros.

Me ha llegado su carta del 3 de Raŷab, en la que me informa usted de la enfermedad de Hasan Bu'ayad, lo siento mucho, y le deseo el bienestar. Es un joven que no cesa de trabajar a favor de Marruecos -haciendo la propaganda para la cuestión berber-.

Es mejor no retardar la publicación de la revista "Le Magreb" hasta el mes de Septiembre, a pesar de toda crisis económica, como os aconsejó Ahmed Balafreŷ. ¿Qué piensa usted? 
Nos ha llegado la revista "La nación árabe", lo mismo para el señor López Ferera. Informaba al residente general, de lo que me había usted indicado en su carta. Además de esto, al estar en Madrid, el señor Canopas -director general de Marruecos y de las colonias- me señala que San le había puesto en guardia contra Ašj Arsalan, que reside en Génova, y que tiene relación con los nacionalistas marroquíes, mediante Bennuna en Tetuán.

Me ha gustado el acuerdo de Siria. Sin duda, los de Siria van a impresionarse por el convencimiento de Fāris Al Jori y Ašahbandar.

De Tánger me ha escrito el señor Arguila, al regresar de la región interior, esperando su alegría por la entrevista con los nacionalistas de allí, sobre todo Hasan Al Wazani, me informó de su viaje a Génova para asistir al congreso de Palestina, sin olvidar de visitaros en su camino.

Al estar en Madrid, he visitado al ministro de instrucción, señor Marcelino Domingo, hemos discutido unas reformas en el dominio de la enseñanza. Lo mismo pasa con el ministro de justicia, Fernando de los Ríos.

En la facultad de Granada, hay un orientalista árabe, van a contratar este año a un profesor y ayudante musulmanes. Pero todavía están discutiendo el programa de los cursos.

Mi hijo Daud, presentó una oposición en la primera sesión celebrada, por el consejo municipal, contra el número de los diputados. Todo esto para cambiar el reglamento de la fundación del consejo municipal, para independizarlo totalmente del gobierno.

Nos ha llegado la convocatoria del congreso musulmán pero me parece difícil asistir. Lo mismo pasa con todos los invitados. Por eso he pedido a mi hermano que nos representaba en este congreso.

Un saludo de 'Abd Salam Ben L'Arbi Bennuna. 